\title{
DIAGNÓSTICO DE PRODUTORES DE SEMENTES E DE PLANTAS NATIVAS DO ESTADO DO RIO GRANDE DO SUL ${ }^{1}$
}

\author{
A SURVEY ON NATIVE SEED AND PLANT PRODUCERS \\ IN THE STATE OF RIO GRANDE DO SUL
}

\section{Eduardo de Medeiros Gass² ${ }^{2}$ Patrícia Goulart Pinheiro³ e Katia Helena Lipp-Nissinen ${ }^{4}$}

\section{RESUMO}

A revegetação é etapa importante nos planos de recuperação de áreas degradadas (PRAD). A escolha adequada de espécies vegetais e o conhecimento das fontes para obtenção dessas são informações importantes para planejamento. No presente estudo, objetivou-se inventariar fontes de plantas nativas, ou seja, viveiros que produzem e/ou comercializam sementes e mudas de plantas nativas no estado do RS, com vistas ao conhecimento de sua aptidão e capacidade ao fornecimento de plantas para a revegetação em PRAD. Uma lista com 102 contatos de viveiros ativos no RS foi obtida a partir de cadastros estadual e nacional e de buscas na internet. Um questionário com 19 perguntas objetivas e dissertativas foi enviado aos endereços eletrônicos de cada um, seguido de reenvio. Os resultados apresentados aqui representam as respostas dos 18 viveiristas que responderam ao questionário. Quase a metade (47\%) das espécies produzidas/comercializadas é nativa do RS. Quatorze viveiros destinam sua produção de mudas e sementes para PRAD, além de outros destinos. A maioria dos viveiristas julgou-se apto a fornecer materiais para PRAD, considerando seus potenciais de produção atuais, e um planejamento prévio para atender as demandas dessa atividade. Demais dados quali-quantitativos levantados incluem produção anual, número, origem, identificação e hábitos vegetativos das espécies, destino, distribuição e assistência pós-venda. Os resultados contribuem para a criação de uma lista de viveiros com informações que poderão subsidiar procedimentos de PRAD no RS.

Palavras-chave: Questionários, Revegetação, Planos de recuperação de áreas degradadas, Viveiros de plantas.

\section{ABSTRACT}

Revegetation is an important step in plans to recover degraded areas (PRAD). The proper choice of plant species and the knowledge of the sources for obtaining them are important information for planning. The present study aimed to survey sources of native plants, that is, nurseries producing and/or commercializing seeds and plants in the state of RS, with a view to knowing their aptitude and capacity to supply plants for revegetation in PRAD. A list with 102 contacts of active nurseries was obtained from State and National registries and searches on the internet. A questionnaire with 19 questions was sent via e-mail, followed by resubmission. The results presented here represent the responses of 18 nurserymen who answered the questionnaire. Almost half (47\%) of the species produced and/or traded are native to RS. Fourteen nurseries devote their production to PRAD, in addition to other destinations. Most nurserymen considered themselves able to supply plant materials for PRAD, considering their current production potentials, and prior planning to meet the demands of this activity. Other quali-quantitative data collected include annual production, number, origin, identification and 1 Trabalho de Iniciação Científica, PIBIC CNPq

2 Bolsista PIBIC CNPq-FEPAM. Graduado em Ciências Biológicas - UFRGS, Porto Alegre. Cursando Especialização em "Ciência é10". E-mail: eduardo_mdg@hotmail.com

3 Bolsista PIBIC CNPq-FEPAM. Graduada em Ciências Biológicas - UFRGS, Porto Alegre. Mestranda no PPG em Educação Científica e Tecnológica - Universidade Federal de Santa Catarina, Florianópolis, SC. E-mail: patgopi@gmail.com 4 Bióloga. Mestre em Botânica e Biotecnologia Vegetal (UFRGS). Doutora em Biologia Celular e Molecular Vegetal (University of Manchester, GB), Analista Bióloga da Divisão de Laboratórios da FEPAM. E-mail: katiahln@fepam.rs.gov.br 
vegetative habits of the species, destination, distribution and after-sales assistance. The results contribute to the creation of a list of nurseries with information that could support PRAD procedures in RS.

Keywords: Nurseries, Questionairies, Revegetation, Degraded areas recovery plans.

\section{INTRODUÇÃO}

As áreas de preservação permanentes (APP), de reserva legal (RL), bem como as unidades de conservação de uso restrito e outras áreas protegidas devem, por determinação legal, manter a sua cobertura vegetal preservada. Como redutos florestais e corredores ecológicos, essas áreas exercem importantes serviços ecossistêmicos em meio à pressão dos usos antrópicos. Dentre esses usos, citam-se atividades agrossilvipastoris em larga escala, de extração mineral e de parcelamento de solo para expansão urbana. Além do impacto paisagístico inerente às atividades, ocorrem alterações no solo e no relevo, que na maioria dos casos, alteram os regimes hídricos superficiais. Ao mesmo tempo, as atividades resultam na supressão da vegetação nativa, com consequente impacto sobre a fauna nativa e o equilíbrio do ecossistema como um todo (LIMA e ZAKIA, 2006).

A Constituição Federal (BRASIL, 1988) determinou a recuperação de áreas alteradas por extração mineral como uma obrigação legal. Para tanto, o licenciamento ambiental dos empreendimentos requer o cumprimento de planos de recuperação de áreas degradadas (PRAD) previamente definidos. Entendendo ser a mineração uma atividade extremamente impactante e de difícil controle,

O Código Florestal de 2012 (Lei No 12.651/2012, alterada pela Lei No 12.727/2012) criou instrumentos que induzem a recuperação de áreas degradadas em APP e RL. Dentre esses se incluem o Cadastro Ambiental Rural (CAR) e o Programa de Regularização Ambiental (PRA), sendo a implantação do PRA, sobretudo, desencadeadora da recomposição de áreas de passivo.

Um dos métodos usados em PRAD, após a eliminação do fator degradante, envolve a regeneração natural, ou seja, um processo de auto-renovação da vegetação, através de uma sucessão lenta e gradual. Enquanto a revegetação intervencionista é uma etapa importante em locais que sofreram desmatamento e requer ações mais diretas, como a semeadura direta e o plantio de mudas de espécies florestais (MORAES et al., 2013). A escolha de espécies vegetais adequadas para cada fase em sucessão no processo de revegetação contribuirá para o seu êxito no retorno a um estado mais similar ao do ecossistema natural. A escolha das plantas depende de conhecimentos que abrangem uma série de fatores, incluindo edáficos, climáticos, fisiológicos, ecológicos, legais, logísticos, dentre outros (SILVA, CAMPAGNA, LIPP-NISSINEN, 2018).

Considerando esse cenário, um aumento na demanda por mudas e sementes para a restauração de áreas se faz provável, na medida em que os instrumentos legais sejam aplicados. Diante 
dessa perspectiva, conforme apontado por Silva et al. (2015), a análise da infraestrutura existente para suprir a demanda assume um papel estratégico no planejamento das ações, sendo importante o conhecimento das espécies vegetais a serem escolhidas e das fontes para sua obtenção. A respeito das fontes, a localização dos viveiros produtores e fornecedores de mudas nativas, a sua capacidade de produção e a qualidade das mudas são fundamentais para orientar os que buscam restaurar áreas, bem como para direcionar as ações que visam incrementar a infraestrutura existente. Porém, conforme Marques, apud Silva (2015), essas informações encontram-se pouco estruturadas ou são ainda inexistentes em diversas regiões do país.

No presente estudo objetivou-se inventariar fontes de plantas nativas, ou seja, empreendimentos públicos ou privados que produzem e/ou comercializam sementes e mudas de plantas nativas no estado do RS, visando o conhecimento de sua aptidão e capacidade ao fornecimento adequado, em especial com vistas à revegetação em projetos de recuperação de áreas degradadas. Os dados são hoje ainda escassos e um diagnóstico similar para o RS não foi encontrado.

\section{METODOLOGIA}

Inicialmente, levantaram-se os nomes e endereços de viveiros produtores de espécies florestais nativas existentes no RS até então (novembro de 2016) presentes em listagem do Departamento de Biodiversidade da Secretaria de Estado do Meio Ambiente e Infraestrutura (DBIO/SEMA-RS). Verificando-se que a lista fornecida continha dados não atualizados ou incompletos, foram realizadas pesquisas na internet. Adicionalmente, buscaram-se informações junto ao RENASEM - Registro Nacional de Sementes e Mudas, no portal do Ministério da Agricultura, Pecuária e Abastecimento (MAPA).

Para servir de instrumento de análise do perfil dos viveiros, tanto sobre a empresa em si, quanto sobre aspectos da produção de mudas e sementes, foi elaborado um questionário na plataforma Google Docs ${ }^{T M}$ com 19 perguntas, objetivas e dissertativas (Quadro 1).

Entre dezembro de 2016 e fevereiro de 2017, o questionário eletrônico foi enviado aos endereços dos produtores constantes na lista revisada. O questionário foi enviado pela segunda vez àqueles empreendimentos sem resposta e, também, foram feitos telefonemas pontuais entre março e maio de 2017. Além disso, foram realizadas visitas e entrevistas semiestruturadas a três viveiros, os quais haviam sido igualmente consultados através do questionário eletrônico, porém não haviam retornado as respostas até então.

Os dados coletados dos questionários respondidos foram inseridos em tabela, em gráficos e analisados. 
Quadro 1 - Questionário sobre Viveiros de Plantas Nativas do RS

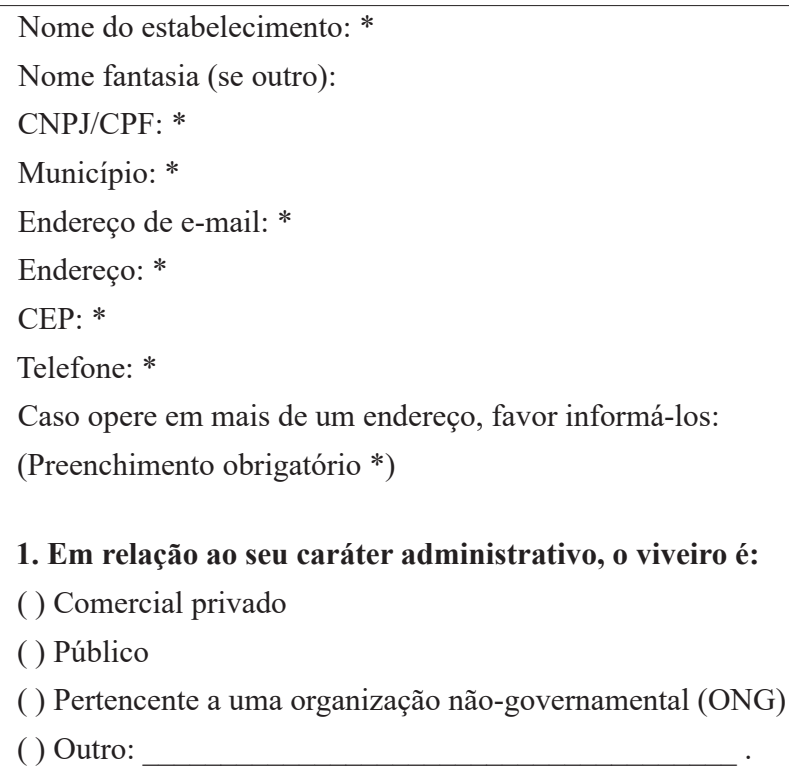

1. Em relação ao seu caráter administrativo, o viveiro é:

( ) Comercial privado

( ) Público

( ) Pertencente a uma organização não-governamental (ONG)

( ) Outro:

2. A área total do viveiro em metros quadrados $\left(\mathrm{m}^{2}\right)$ ocupa:

( ) Menos de $1.000 \mathrm{~m}^{2}$

() Entre 1.001 e $5.000 \mathrm{~m}^{2}$

( ) Entre 5.001 e $10.000 \mathrm{~m}^{2}$

( ) Entre 5.001 e $10.000 \mathrm{~m}^{2}$

() Entre 10.001 e $25.000 \mathrm{~m}^{2}$

() Mais de $25.001 \mathrm{~m}^{2}$

2.1 Em relação à questão anterior, informe a área total aproximada do viveiro:

3. Qual a produção média anual de mudas?

( ) Até 50.000 mudas

( ) De 50.001 a 100.000 mudas

() De 100.001 a 200.000 mudas

( ) De 200.001 a 300.000 mudas

( ) Mais de 300.001 mudas

( ) Informação desconhecida

3.1 Em relação à questão anterior, informe a produção média anual aproximada de mudas:

4. Quantas espécies são produzidas/comercializadas pelo viveiro:

( ) Até 25 espécies

( ) De 26 a 50 espécies

( ) De 51 a 75 espécies

( ) De 76 a 100 espécies

() Mais de 101 espécies

( ) Informação desconhecida 
5. É possível informar a porcentagem (\%) aproximada de plantas quanto ao hábito vegetativo das espécies produzidas no viveiro?

() $\mathrm{Sim}$

( ) Não

Arbóreas:

Arbustivas:

Epífitas:

Herbáceas:

Trepadeiras:

6. É possível informar a porcentagem (\%) de plantas nativas e/ou exóticas entre as espécies produzidas no viveiro? ( ) $\mathrm{Sim}$

( ) Não

Nativas do Rio Grande do Sul (RS):

Nativas do Brasil:

Exóticas ao RS: Exóticas ao Brasil:

7. Quanto à finalidade das mudas e/ou sementes, o viveiro realiza:

( ) Comércio

( ) Doação

( ) Uso próprio

( ) Outro:

8. Se há comércio, qual o principal produto comercializado?

( ) Mudas

( ) Sementes

( ) Ambos

( ) Outro:

9. Quanto ao destino do material vegetal, o viveiro promove principalmente (assinale todas alternativas aplicáveis):

( ) Arborização urbana

( ) Recuperação de áreas degradadas

( ) Recomposição florestal

( ) Paisagismo e/ou jardinagem

( ) Outro:

10. O viveiro possui convênio com alguma instituição ou empresa?

( ) $\mathrm{Sim}$

( ) Não

10.1 Em caso de resposta afirmativa à questão anterior, citar a instituição ou empresa:

11. Quanto à coleta de semente, $o$ viveiro (assinale todas as alternativas aplicáveis):

( ) Coleta as próprias sementes

( ) Compra sementes de produtores

() Troca sementes com outros viveiros

( ) Outra: 
12. A identificação das espécies é feita por (assinale todas as alternativas aplicáveis):

( ) Especialistas botânicos

( ) Técnicos agrícolas

( ) Outro:

13. O viveiro realiza a marcação/identificação das árvores matrizes:

( ) $\mathrm{Sim}$

( ) Não

14. No viveiro, as plantas são encontradas identificadas pelos seus nomes:

( ) Científicos

( ) Populares

( ) Ambos

15. O viveiro realiza algum tratamento preventivo e/ou para a desinfecção/desinfestação das mudas e/ou sementes? (Assinale todas as alternativas aplicáveis.)

( ) Fungicidas

( ) Inseticidas

( ) Bactericidas

() Outro:

16. O viveiro disponibiliza uma tabela de preços das mudas e/ou sementes?

( ) $\mathrm{Sim}$

( ) Não

17. O viveiro encarrega-se do transporte e distribuição das mudas e/ou sementes?

( ) $\mathrm{Sim}$

( ) Não

17.1 Em caso de resposta afirmativa à questão anterior, quais veículos utilizados? (Assinale todas as alternativas aplicáveis.)

( ) Caminhão climatizado/frigorífico

( ) Outro:

18. Quanto à assistência pós-venda, o viveiro (assinale todas as alternativas aplicáveis):

( ) Oferece orientações técnicas ao plantio

( ) Acompanha o plantio e sua manutenção

( ) Não dispõe de assistência pós-venda

( ) Outro:

18.1 Em caso de qualquer tipo de assistência pós-venda, informe como ela se dá (por exemplo, somente por internet, pessoalmente, no rótulo do produto, etc.):

19. Conforme o objetivo deste levantamento, responda sobre as seguintes questões.

(a) Julga o seu estabelecimento apto a fornecer material para a recuperação de áreas degradadas, considerando as suas capacidades atuais e potenciais ao atendimento a este mercado?

(b) Possui interesse nesta área de atuação?

(c) Verifica algum obstáculo para tal? Justifique 


\section{RESULTADOS E DISCUSSÃO}

Do total de 102 viveiros, apenas 18 responderam ao questionário, o que é equivalente a aproximadamente $18 \%$ do total. Além desses 18 , foram recebidos telefonemas e mensagens de e-mail de sete produtores, buscando maiores esclarecimentos sobre o questionário. Esses viveiristas, que não haviam respondido ao questionário, enviaram as seguintes justificativas: dois (02) informaram estarem inativos, três (03) não serem produtores, mas, sim, revendedores de plantas, enquanto outros dois (02) informaram não produzirem ou comercializarem espécies nativas, e, sim, exóticas cultivadas com finalidades ornamentais, agrícolas ou silvícolas.

Para análise e interpretação de dados, foram consideradas as respostas dos 18 viveiros que responderam ao questionário, não sendo contabilizados, junto ao número absoluto de viveiros consultados, aqueles endereços eletrônicos inválidos ou desatualizados.

Dentre as causas do alto número de não respostas é possível se supor que uma parte dos empreendimentos não mais se enquadrava no perfil pesquisado. É também possível que muitos viveiristas tenham evitado responder através da rede eletrônica por receio de exporem dados pessoais e empresariais, ou, ainda, por suspeitarem que a pesquisa fosse relacionada à fiscalização. A não familiaridade com a plataforma Google ${ }^{\mathrm{TM}}$ para inserir suas respostas, o desinteresse em colaborar voluntariamente com uma pesquisa não-obrigatória, e a falta de pessoal e tempo disponível também podem ser justificativas do baixo número de retornos. Outra possibilidade é a ocorrência de endereços desatualizados ou páginas eletrônicas de viveiros inativos ainda publicadas na internet.

Similarmente, uma baixa porcentagem relativa de produtores respondentes foi obtida por Gonçalves (2004). Esse autor enviou 853 questionários para diagnosticar os viveiros municipais do estado de Minas Gerais e obteve 270 (31\%) respostas.

Verificou-se, durante este estudo, que as informações de contato, eletrônico ou de telefone, dos produtores de mudas e sementes, contidas no sistema do RENASEM/MAPA na internet não estavam abertas ao público. Ou seja, aparentemente, o sistema estaria destinado para as funções de cadastro e registro e não para a função de consulta externa, inviabilizando o acesso público às informações, conforme também foi observado por Silva et al. (2015). Posteriormente à presente pesquisa, para Teixeira et al. (2018), os dados do RENASEM permitiram a localização e o mapeamento de 310 viveiros cadastrados no RS, embora, além da localização espacial, aquele estudo não apresentou outras informações sobre os mesmos.

\section{CATEGORIAS ADMINISTRATIVAS DOS VIVEIROS}

Quanto à caracterização administrativa, 13 viveiros respondentes $(72,2 \%)$ classificam-se como comerciais privados, três (16,7\%) são públicos, um (5,6\%) é cooperativa e um (5,6\%) é unidade 
comunitária (Figura 1). Nenhum dos viveiros respondentes se constitui em uma organização da sociedade civil (ONGs) (Figura 1). Em outro levantamento, realizado para diagnosticar viveiros de todo Brasil, os empreendimentos privados também foram em maior número, com porcentagem de 70,7\%. Segundo Silva (2015), esse resultado pode representar a ausência de levantamentos junto às prefeituras municipais sobre a existência de viveiros e sua potencial participação na pesquisa.

Figura 1 - Número, por categorias administrativas. dos viveiros florestais do Rio Grande do Sul participantes na pesquisa.

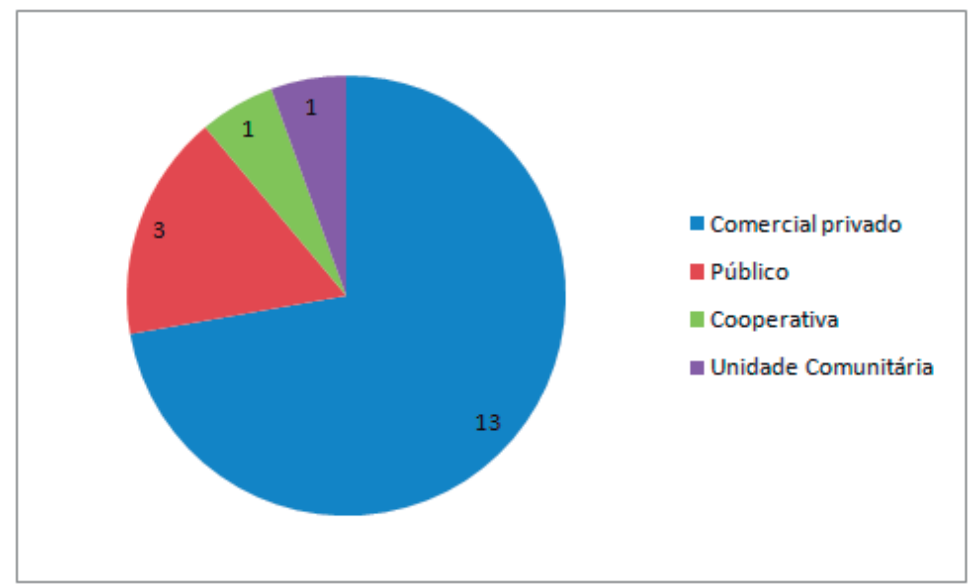

\section{ÁREA TOTAL DOS VIVEIROS}

Observa-se ampla variação com relação à área total ocupada pelos viveiros (Figura 2). Os de caráter comercial privado geralmente possuem maior área ocupada, ficando entre $10.001 \mathrm{~m}^{2}$ e 25.000 $\mathrm{m}^{2}$ ou mais que $25.001 \mathrm{~m}^{2}$ - com exceção de um viveiro privado com área entre $5.001 \mathrm{~m}^{2}$ e $10.000 \mathrm{~m}^{2}$. Os três viveiros públicos que responderam possuem áreas entre $1.001 \mathrm{~m}^{2}$ e $5.000 \mathrm{~m}^{2}$, já a unidade comunitária ocupa entre $5.001 \mathrm{~m}^{2}$ e $10.000 \mathrm{~m}^{2}$, enquanto a da cooperativa entre 10.001 e $25.000 \mathrm{~m}^{2}$. Dentre os respondentes, não foram encontrados viveiros com áreas menores do que $1.000 \mathrm{~m}^{2}$ (Figura 2).

Figura 2 - Percentual de viveiros florestais do Rio Grande do Sul, participantes da pesquisa, representados por área de ocupação em metros quadrados $\left(\mathrm{m}^{2}\right)$.

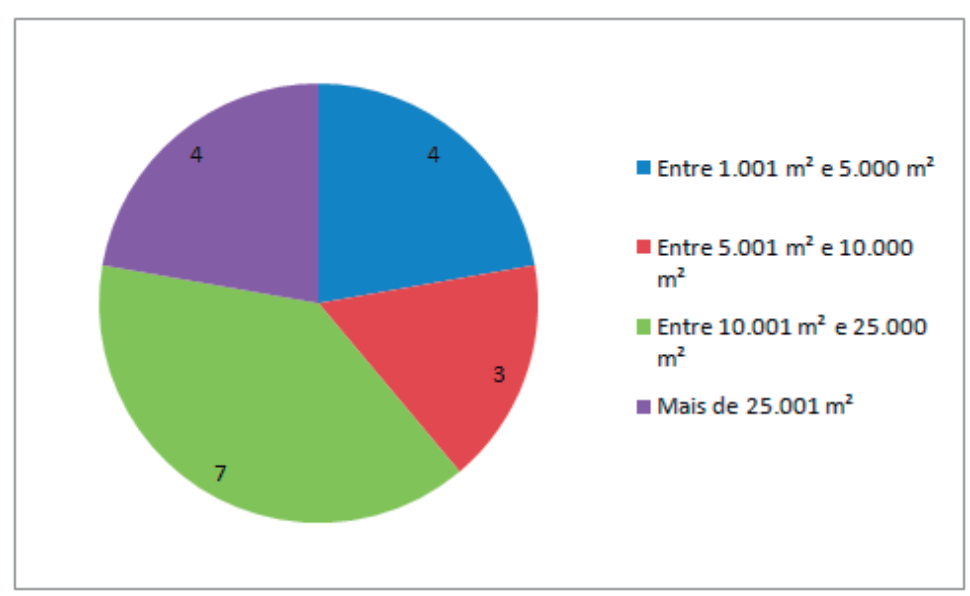


PRODUÇÃO MÉDIA ANUAL DE MUDAS

A maioria (10) dos viveiros respondentes apresentou uma baixa produção média anual (até 100.000 mudas por ano). Seis viveiros informaram ter alta produção (mais de 300.001 mudas por ano), enquanto uma minoria dos respondentes informou valores intermediários de produção média anual, considerando as faixas de produção pré-estabelecidas pela pesquisa (Figura 3).

Figura 3 - Produção média anual de mudas em viveiros florestais do Rio Grande do Sul, respondentes à pesquisa.

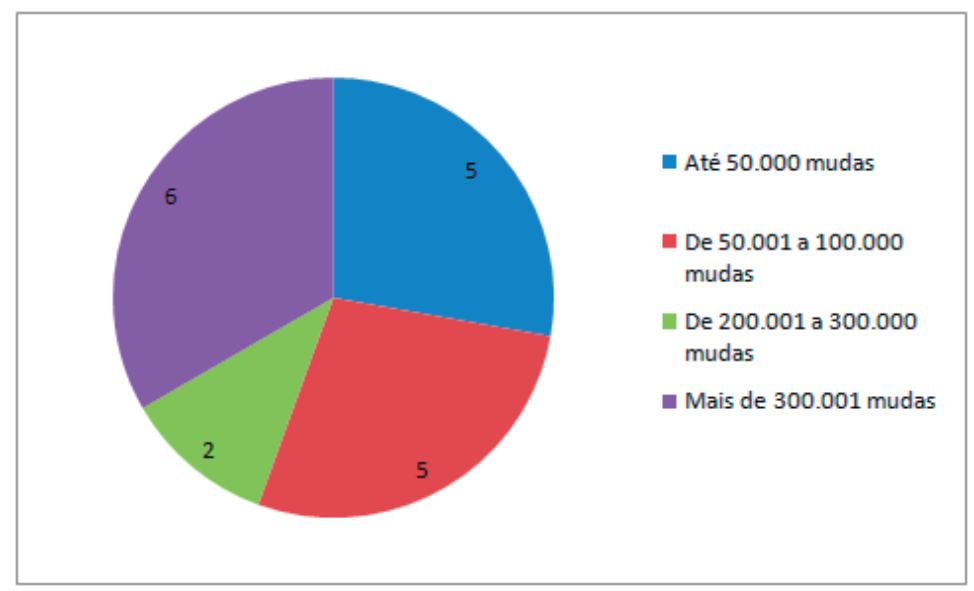

\section{ESPÉCIES VEGETAIS PRODUZIDAS}

Mais da metade (72,2\%) dos viveiros produz/comercializa uma variedade de até 75 diferentes espécies. Apenas 27,3\% dos viveiros produzem/comercializam acima de 75 espécies (Figura 4).

Figura 4 - Número de espécies produzidas pelos viveiros florestais do Rio Grande do Sul respondentes à pesquisa.

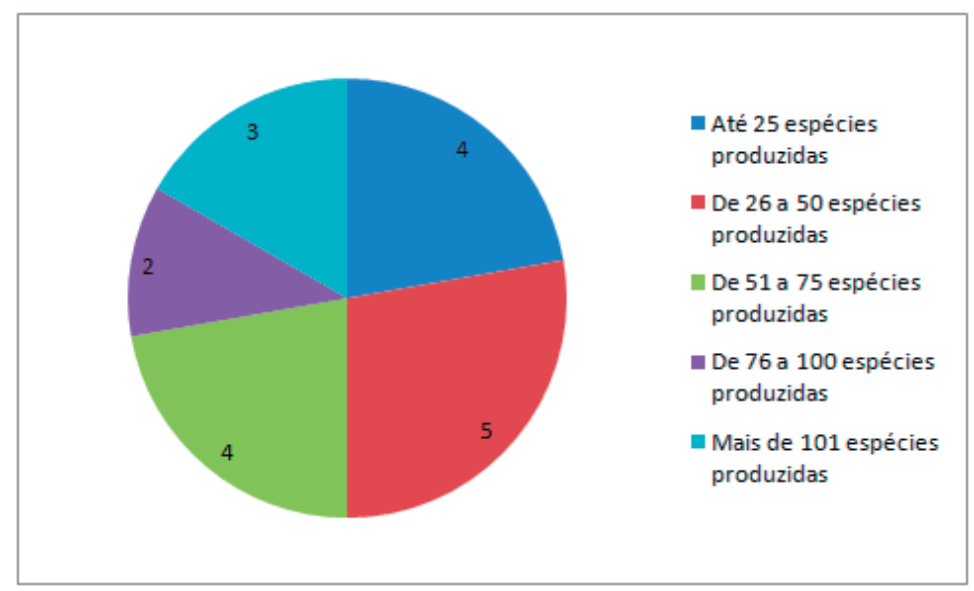

\section{HÁBITO VEGETATIVO DAS ESPÉCIES PRODUZIDAS}

A maioria dos viveiros respondentes produz espécies de hábito arbóreo, sendo essas em média $81 \%$ da produção total. Plantas de hábito arbustivo apareceram em segundo lugar (11\%), enquanto 
os hábitos epífito, herbáceo e de trepadeira somados chegaram a 7\% da produção (Figura 5). Dois viveiros não souberam afirmar a porcentagem aproximada dos hábitos vegetativos das espécies que produzem.

Figura 5 - Quantidade (em percentual) da produção/comércio das espécies quanto ao hábito vegetativo, pelos viveiros florestais do Rio Grande do Sul participantes da pesquisa.

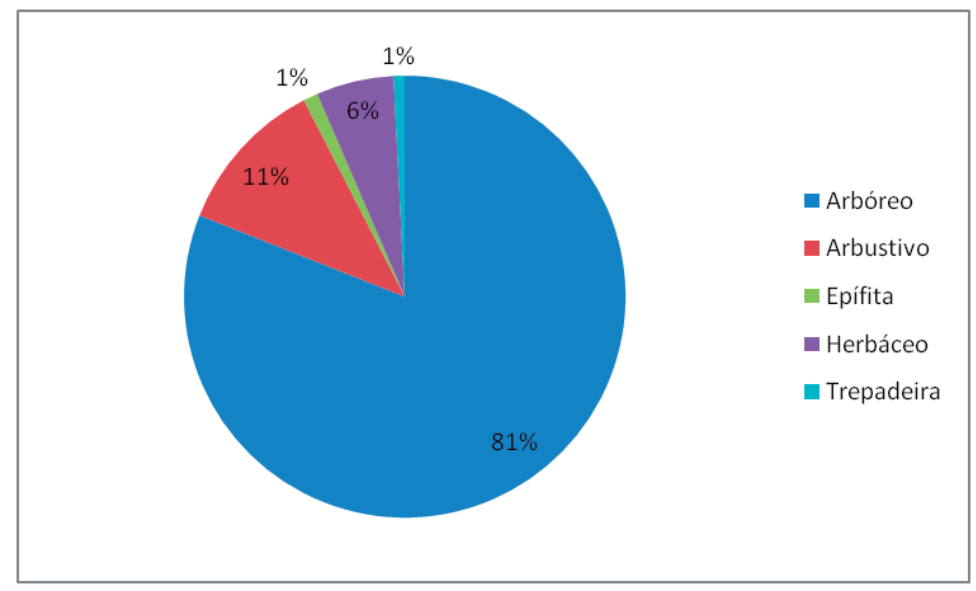

\section{REGIÃO DE ORIGEM DAS ESPÉCIES}

Para a maioria dos respondentes (16 dos 18 viveiros) pouco menos da metade (47\%) das espécies produzidas/comercializadas são nativas do Rio Grande do Sul, enquanto 8\% são nativas do Brasil. As espécies exóticas do Rio Grande do Sul e do Brasil representam 25\% e 20\%, respectivamente, da produção/comercialização (Figura 6). Apenas dois não souberam informar sobre as quantidades de espécies que produzem segundo a sua origem natural.

Figura 6 - Distribuição percentual quanto à origem natural, se nativas ou exóticas, das espécies produzidas/comercializadas pelos viveiros florestais do Rio Grande do Sul participantes da pesquisa.

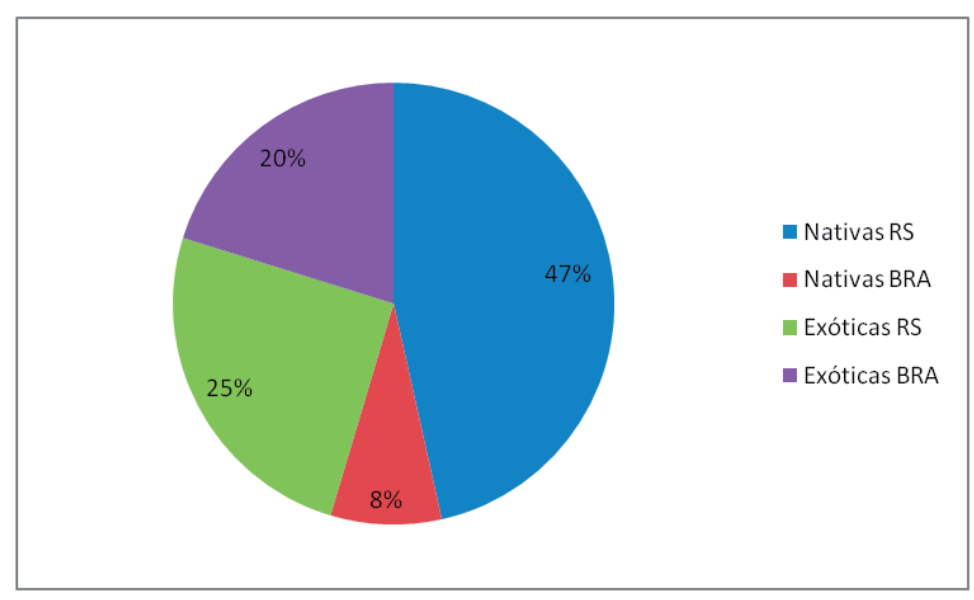


Quanto à finalidade das mudas e sementes produzidas, 13 dos respondentes realizam apenas comércio, um faz comércio e doação, outro faz comércio e uso próprio, e outro, ainda, comércio, doação e uso próprio, totalizando 16 viveiros que comercializam o material vegetal que é produzido. Os restantes dois viveiros produzem somente para doação e uso próprio.

\section{PRODUTOS COMERCIALIZADOS}

Dos 16 respondentes que comercializam sua produção, 15 viveiros comercializam apenas mudas e um comercializa mudas e sementes.

\section{DESTINO DO MATERIAL VEGETAL}

Verificou-se uma grande variedade de destinos dos materiais vegetais produzidos nos viveiros. Treze viveiros responderam que destinam sua produção para arborização urbana, recuperação de áreas degradadas e recomposição florestal. Oito informaram destinar sua produção para paisagismo e seis viveiros indicaram outros destinos.

\section{RELAÇÃO COM OUTRAS INSTITUIÇÕES}

Apenas quatro dos respondentes possuem convênio com outras instituições empresariais.

\section{OBTENÇÃO DE SEMENTES}

Seis viveiros obtêm suas sementes somente por meio de compra. Outros quatro viveiros, além de comprar, também coletam suas próprias sementes, enquanto outros dois viveiros, além dessas atividades, ainda realizam trocas de sementes. Dos 18 viveiros respondentes, quatro praticam apenas coleta de suas próprias sementes e outros dois apenas coletam e trocam sementes. Apesar de a maioria dos viveiros não fazer intercâmbio de sementes, este pode ser um meio bastante útil para aumentar a diversidade de espécies produzidas (Silveira Filho e Freschi, 2010).

\section{IDENTIFICAÇÃO DAS ESPÉCIES}

Nove viveiros declararam identificar as espécies vegetais apenas por nome popular, um por nome científico apenas e oito utilizam ambas as nomenclaturas. 
Em cinco viveiros a identificação botânica das espécies é feita apenas por técnicos agrícolas. Outros três viveiros informaram que a identificação é realizada apenas por engenheiros agrônomos. Especialistas botânicos e os proprietários dos estabelecimentos identificam as espécies produzidas/ comercializadas em outros dois viveiros. Nos oito viveiros restantes, a identificação é feita por equipes com dois ou três dos profissionais listados acima, alguns com auxílio de funcionários experientes sem qualificação formal.

\section{MARCAÇÃO DE ÁRVORES MATRIZES}

Apenas 10 viveiros afirmaram realizar a marcação das árvores matrizes das sementes e mudas. A referência de origem genética, ou seja, a marcação das matrizes é importante para o controle e qualidade das sementes e mudas produzidas nos viveiros (Almeida et. al., 2007).

\section{TRATAMENTOS PREVENTIVOS}

A maioria dos viveiros opta por tratamentos com fungicidas e inseticidas em suas mudas, podendo ser somente o uso de fungicidas (04), somente uso de inseticidas (02), ambos os produtos em combinação (04), ou, ainda, ambos combinados com bactericidas (03). Outras formas também foram verificadas, porém empregadas em menores proporções em relação aos tratamentos listados acima: uso concomitante de repelentes orgânicos e inseticidas (01), ou bactericidas juntamente com fungicidas (01). Dois viveiros não realizam nenhum tipo de tratamento preventivo e apenas um, outro, realiza controle biológico: o viveiro do Jardim Botânico da Fundação Zoobotânica do Rio Grande do Sul (JB/FZBRS, Porto Alegre).

\section{ACESSO AO PREÇO}

A metade dos viveiros (09) que responderam ao questionário disponibiliza tabelas de preços referentes aos materiais vegetativos que produzem/comercializam.

\section{TRANSPORTE E DISTRIBUIÇÃO}

Mais da metade dos viveiros entrevistados $(61,1 \%)$, ou seja, 11 viveiros encarregam-se do transporte de seus materiais comercializados. Outros seis viveiros terceirizam os serviços de transporte e a distribuição. 


\section{VEÍCULOS UTILIZADOS NO TRANSPORTE}

O transporte/distribuição dos produtos comercializados por 12 viveiros é feito através de caminhões/furgões, sendo apenas a metade (06) desses veículos climatizada.

\section{ASSISTÊNCIA PÓS-VENDA}

Doze dos viveiros dispõem de algum tipo de assistência pós-venda ao cliente, seja através de acompanhamento e manutenção do plantio (um viveiro), de orientações técnicas ao plantio (04 viveiros), ou ainda de ambos os modos (07 viveiros). O restante dos viveiros (06) não fornece qualquer tipo de assistência pós-venda.

\section{POTENCIAIS, INTERESSES E OBSTÁCULOS}

A maioria dos produtores afirmou julgar-se apto a fornecer materiais à recuperação de áreas degradadas (RAD), levando em consideração seus potenciais de produção atuais. Além disso, possuem interesse nesse campo de atuação (RAD). Apenas dois viveiros consideraram que suas produções e áreas de atuação não se aplicavam à presente pesquisa. Quando questionados sobre possíveis obstáculos à produção destinada a área de RAD, aproximadamente metade dos viveiros respondeu que não vê empecilhos, desde que haja um planejamento prévio para atender as demandas dessa atividade. Parte do restante dos produtores encontra os seguintes obstáculos nessa área de atuação: fiscalização, exigência das leis ambientais e falta de incentivo (02 viveiros); carência de demanda por produção a essa finalidade (um viveiro); competição, em geral com outros produtores, além do comércio ilegal (um viveiro) e dificuldades na obtenção de sementes (um viveiro).

\section{CONCLUSÕES}

Verificou-se desatualização nas listagens consultadas de produtores de plantas e/ou sementes nativas. Após pesquisas para confirmação dos endereços, 102 viveiros receberam um questionário elaborado com 19 perguntas, objetivando conhecer a localização dos produtores e fornecedores, seus procedimentos, a capacidade de produção, os materiais, sua origem e qualidade, dentre outros dados. Dos 102 viveiros consultados apenas 18 responderam o questionário (18\% do total), mesmo com reenvio. Pouco mais da metade (55\%) dos viveiros informou uma produção média anual de até 100.000 mudas/ ano, enquanto 33\% produzem mais de 300.000 mudas/ano. Quase a metade (47\%) das espécies produzidas/comercializadas é nativa do RS. Sobre o método de obtenção, 44\% dos respondentes pratica a coleta de suas próprias sementes e $22 \%$ realiza a troca de sementes. Quanto à diversidade, cerca de $30 \%$ dos viveiros produz/comercializa mudas de mais de 75 espécies nativas. Quatorze viveiros destinam sua 
produção de mudas e sementes para PRAD, além de outros destinos. A maioria dos produtores julgou-se apto a fornecer materiais a PRAD, considerando seus potenciais de produção atuais e um planejamento prévio para atender as demandas dessa atividade. Os resultados contribuem para a criação de uma lista de viveiros fornecedores de espécies nativas no RS. As informações obtidas podem subsidiar ações de planejamento, assim como auxiliar trabalhos de restauração de áreas degradadas.

\section{REFERÊNCIAS}

ALMEIDA, D. S. et al. Diagnóstico dos viveiros de produção e mudas nativas da mata atlântica existentes nos estados da Bahia e Espírito Santo. RIOESBA, Porto Seguro, outubro, 2007. Disponível em: https://bit.ly/3DWSuNC. Acesso em: 17 abri. 2017.

BRASIL. Constituição da República Federativa do Brasil, 5 de outubro de 1988. Brasília, DF: Senado Federal, 1988. Palácio do Planalto: Presidência da República. Disponível em: https://bit.ly/ 3poQcTu. Acesso em: 06 mai. 2021.

BRASIL. Lei Federal N ${ }^{\circ}$ 12.651, de 25 de maio de 2012a. Disponível em: http://www.planalto.gov.br/ ccivil/Leis/. Acesso em: 17 abril 2021.

BRASIL. Lei Federal N 12.727, de 17 de outubro de 2012b. Disponível em: https://bit.ly/3ndY47M. Acesso em 19 abril 2021.

GONÇALVES, E. O.; PAIVA, H. N.; JACOVINE, L. A. G.; GONÇALVES, W. Diagnóstico dos viveiros municipais no estado de Minas Gerais. Ciência Florestal (UFSM. Impresso), Santa Maria, v. 14, n.2, p. $1-12,2004$.

LIMA, W. P.; ZAKIA, M. J. B. O papel do ecossistema ripário. In: LIMA, W. P.; ZAKIA, M.J.B. (Org.). As florestas plantadas e a água: Implementando o conceito da microbacia hidrográfica como unidade de planejamento. São Carlos: RiMa, 2006. p. 77-87.

MORAES, L. F. D.; ASSUMPÇÃO, J. M.; PEREIRA, T. S.; LUCHIARI, C. MANUAL técnico para a restauração de áreas degradadas no Estado do Rio de Janeiro. Jardim Botânico do Rio de Janeiro, 2013. 84 p.: il. ISBN 978-85-60035-11-3. 
SILVA, I. A.; CAMPAGNA, A. R.; LIPP-NISSINEN, K. H. 2018. Recuperação de áreas degradadas por mineração: uma revisão de métodos recomendados para garimpos. Pesquisas em Geociências, v. 45: e0691. DOI: https://doi.org/10.22456/1807-9806.91386.

SILVEIRA FILHO, T. B. S.; FRESCHI, J. M. (Org.). Diagnóstico da produção de mudas de espécies nativas do estado do Rio de Janeiro. SEA, Rio de Janeiro, 2010. Disponível em: https://bit.ly/3ne6jRa. Acesso em: 07 jul. 2017.

TEIXEIRA, A. A. D.; NORONHA, A. H.; FREITAS, T. C.; CUNHA, H. N., MIURA, A. K.; GUARINO, E. S. G. Levantamento de viveiros dos estados de Santa Catarina e Rio Grande do Sul cadastrados no RENASEM/MAPA. Cadernos de Agroecologia, ISSN 2236-7934, Anais do VI CLAA, X CBA e V SEMDF, v. 13, n. 1, jul. 2018. 